\title{
Methods review of recycling mercury from waste mercury chloride catalyst of PVC production
}

\author{
Zinan Xie ${ }^{\mathrm{a}}$, Xia Wang ${ }^{\mathrm{b}}$ \\ ${ }^{1}$ School of Materials and chemical engineering, Tongren University, GuiZhou 554300, China; \\ ${ }^{\mathrm{a} X z n 8821 @ 163 . c o m,{ }^{\mathrm{b}} 75198617 @ q q . c o m}$
}

Keywords: waste mercury catalyst, PVC production, recovery of mercury

\begin{abstract}
Serious pollution of waste gas, waste water and waste residue are generated by calcium carbide-based polyvinyl chloride (PVC) production in China, especially the mercury pollution on account of using a mass of mercury chloride catalyst $\left(\mathrm{HgCl}_{2}\right)$. This study introduced main methods and techniques which were grouped into fire metallurgy and hydrometallurgy respectively for recycling mercury from waste mercury chloride catalyst of PVC production. The different process conditions and recovery effect of mercury of these methods were illustrated in this paper.
\end{abstract}

\section{Introduction}

Mercury is one of the most hazardous metals because of its ability to evaporate in soil or water. It is extremely dangerous ${ }^{[1]}$. 3600t mercury worldwide enter into the environment each year. Mercury emissions mainly comes from the two parts of natural and artificial sources. Natural source mainly comes from the natural release by geological source. Artificial sources refers to mercury emissions, including the use of mercury, mercury content of impurities and waste mercury disposal such three categories. China is now the largest source of mercury emissions. China emits at least $700 \mathrm{t}$ of mercury per year, mainly from coal combustion, metal smelting, and cement production, which is $1 / 4$ of the global emissions ${ }^{[2]}$.

Mercury chloride catalyst produced by PVC production is one of the largest mercury consumption. Unlike other countries, most of PVC (80.9\%) produced in China is made though the calcium carbide process because China has larger source of coal than oil. It has been estimated that to produce $1 \mathrm{t}$ of PVC through the calcium carbide process used $1 \mathrm{~kg}-2 \mathrm{~kg}$ of mercury-impregnated catalyst is consumed. $700 \mathrm{t}-1200 \mathrm{t}$ mercury chloride catalyst has been consumed by calcium carbide process in 2009 , but $50 \%$ of the mercury chloride cannot be recycled ${ }^{[3]}$. And according to our knowledge, there is few report about the review of recycling mercury from waste mercury chloride catalyst of PVC production systematically and detailedly up to now.

The aim of this paper is to summarize the methods of recycling mercury from waste mercury chloride catalyst and provide research foundation for new methods and techniques of recycling mercury source.

\section{Ways of mercury flow and emissions in PVC production}

There are four main ways of mercury flow and emissions:1 waste mercury chloride catalyst; (2)waste activated carbon; (3)waste hydrochloric acid; (4)translating into sublimation mercury. The possession proportion to used mercury chloride catalyst were shown respectively in table 1 .

Table 1 Ways of mercury flow and emissions in PVC production

\begin{tabular}{cc}
\hline Ways of mercury flow and emissions & The proportion \\
\hline Waste mercury chloride catalyst & $33 \%$ \\
Waste activated carbon & $15 \%$ \\
Waste hydrochloric acid & $18 \%$ \\
translating into sublimation mercury & $15 \%$ \\
Others & $19 \%$ \\
\hline
\end{tabular}


The mercury chloride catalyst normally contains $10.5 \%-12.5 \% \mathrm{HgCl}_{2}$, which can sublimate out quite a number of $\mathrm{HgCl}_{2}$ which react with acetylene and generate $\mathrm{Hg}_{2} \mathrm{Cl}_{2}$ under the transformation temperature of $180{ }^{\circ} \mathrm{C}^{[4]}$. $\mathrm{Hg}_{2} \mathrm{Cl}_{2}$ will produce serious harm to water resource. Sublimation $\mathrm{HgCl}_{2}$ will react with hydrogen and generate $\mathrm{Hg}^{0}$ at the same time. It is very deadly that $\mathrm{Hg}^{0}$ will be vented to atmosphere when catalyst was replaced. The solution is to use low-mercury catalyst and non-mercury catalyst. Low-mercury catalyst contains $5 \%-6.5 \% \mathrm{HgCl}_{2}$ and is not easy to sublimate out $\mathrm{HgCl}_{2}$ under temperature of $180{ }^{\circ} \mathrm{C}^{[5]}$. Many attempts have been made to research and development new-type non-mercury catalyst at home and abroad.

Another main flow and emitters of mercury is waste mercury chloride catalyst which is substituted from the front desk for catalytic converter when acetylene conversion rate less than $75 \%$. Waste mercury chloride catalyst has adsorbed a large amount of hydrogen chloride gas, as a result the aqueous solution is strongly acidic and mercuric. It is a highly toxic and corrosive waste, mercury is in commonly $2 \%$ to $5 \%$, a small number of as high as $8 \%$. Therefore, recovering mercury and other useful materials from waste mercury chloride catalyst is far-reaching significance to environment and resources.

\section{Methods of recycling waste mercury chloride catalyst}

The recovery process can be divided into two major categories of fire metallurgy and hydrometallurgy.

Fire metallurgy method. The traditional fire metallurgy process is that using waste mercury chloride catalyst soak or boil hot with $10 \% \sim 15 \% \mathrm{NaOH}$ or $15 \% \mathrm{Na}_{2} \mathrm{CO}_{3}$ or lime (calcium oxide of $20 \%$ ). So $\mathrm{HgCl}_{2}$ is transformed into $\mathrm{HgO}$. And then put $\mathrm{HgO}$ in metal cans, heat indirectly to $700^{\circ} \mathrm{C}$ $\sim 800^{\circ} \mathrm{C}$, making it to mercury vapor and recycling metal mercury via condensation. The reaction mechanism is as follows ${ }^{[6]}$ :

$$
\begin{gathered}
\mathrm{HgCl}_{2}(\mathrm{aq})+\mathrm{NaOH}(\mathrm{aq}) \rightarrow \mathrm{Hg}(\mathrm{OH})_{2}(\mathrm{~s})+2 \mathrm{NaCl}(\mathrm{aq}) \\
\mathrm{Hg}(\mathrm{OH})_{2}(\mathrm{~s}) \rightarrow \mathrm{HgO}(\mathrm{s})+\mathrm{H}_{2} \mathrm{O} \\
2 \mathrm{HgO}(\mathrm{s}) \stackrel{\Delta}{\longrightarrow} 2 \mathrm{Hg}(\mathrm{g})+\mathrm{O}_{2}(\mathrm{~g}) \\
\mathrm{Hg}(\mathrm{g}) \stackrel{\text { Condensation }}{\longrightarrow} \mathrm{Hg}(\mathrm{s})
\end{gathered}
$$

Although this process has been industrialized production, but mercury recovery rate is only about $65 \%$. There are still many technical problems that high energy consumption, escaping risk of mercury vapour, dust combined with mercury need to be solved. At present, carbonization method charging with oxygen of recycling waste mercury chloride catalyst is the most advanced new technology ${ }^{[7,8]}$ Recovering $\mathrm{HgCl}_{2}$ directly from activated carbon to avoid many disadvantages, such as low recovery rate and complex conversion process. The overall recovery efficiency of $\mathrm{HgCl}_{2}$ can reach above 99\%. But carbonization method charging with oxygen is still patented technology. On the Other hand, it is an arduous task that upgrading and the operation cost of production equipment is expensive for many small and medium-sized enterprise of PVC production by calcium carbide.

Hydroetallurgy method. Recycling waste mercury chloride catalyst by hydroetallurgy method do not use conventional high temperature roasting or heating furnace, and recycle metal mercury or other useful components in the solution. Many new recycling technology is developing. It is also a research hotspot that adopting pretreatment, solidification/stabilization or chemical activation method to recycle $\mathrm{Hg}$ and other useful material from waste mercury chloride catalyst.

Such as Yunren Qiu ${ }^{[9]}$ used acidification-ultrasound recycling waste mercury chloride catalyst. The product can be used for mercury catalyst preparation and the process is high efficiency, low energy consumption. Zailiu Yuan ${ }^{[10]}$ invented a method which made waste mercury catalyst had more application, there was no waste water discharge, low energy consumption and mercury recovery rate of $97 \%$ or more through the combination step of soaking, alkaline leaching, reduction and filtering. 
Guangren $\mathrm{Yu}^{[11]}$ dealed with the mercury waste chloride catalyst by pretreatment of using functional solvent I for removing impurity, and extracting $\mathrm{Hg}$ ( II ) and mercury compound with functional solvent II. The recovery of Hg was over 99.9\%, solvent I and solvent II all could recycle, and mercury content in the catalyst was less than $0.01 \%$. Jianxin $\mathrm{Zhu}^{[12-13]}$ added sodium sulphide for additives by means of mechanical ball mill to solidify and stabilize waste mercury catalyst. Mercury leaching value was lower than the United States environmental protection standard limit of $0.2 \mathrm{mg} / \mathrm{L}$ of hazardous wastes and the Chinese national hazardous waste identification standard limit of 0.1 $\mathrm{mg} / \mathrm{L}$. The specific circumstances of the above several patents as shown in table 2.

Table 2 Specific circumstances of several hydroetallurgy method to recycle waste mercury chloride catalyst

\begin{tabular}{|c|c|c|c|}
\hline $\begin{array}{c}\text { The } \\
\text { patent } \\
\text { number }\end{array}$ & Basic method & Additives & Effect \\
\hline$(1)$ & $\begin{array}{c}\text { Combination step of } \\
\text { Acidification-ultrasound }\end{array}$ & $\begin{array}{l}\text { Neutralizing } \\
\text { agent }\end{array}$ & $\begin{array}{l}\text { High efficiency, low energy } \\
\text { consumption }\end{array}$ \\
\hline (2) & $\begin{array}{l}\text { Soaking, alkaline leaching, } \\
\text { reduction and filtering }\end{array}$ & $\begin{array}{l}\mathrm{Sb}(\mathrm{s}) \text { and } \\
\mathrm{Sb}(\mathrm{OH})_{3}(\mathrm{~s})\end{array}$ & Recovery rate of $\mathrm{Hg}$ was $97 \%$ \\
\hline (3) & $\begin{array}{l}\text { Pretreatment and solvent } \\
\text { extraction }\end{array}$ & $\begin{array}{l}\text { Solvent I and } \\
\text { solvent II }\end{array}$ & $\begin{array}{c}\text { Recovery of Hg was over } \\
99.9 \%\end{array}$ \\
\hline (4) & Mechanical ball mill & $\mathrm{Na}_{2} \mathrm{~S}$ & $\begin{array}{l}\text { Mercury leaching value was } \\
\text { lower than } 0.1 \mathrm{mg} / \mathrm{L}\end{array}$ \\
\hline
\end{tabular}

Such a large number of studies have shown that it is essential to recycle mercury resources though continuous research of new type solidifying and recycling process.

\section{Summary}

The recycling methods of mercury from waste mercury chloride catalyst are introduced in this paper. The methods mainly include fire metallurgy and hydroetallurgy. Traditional fire metallurgy is mature but the effect of mercury recycling is low and severe pollution. New fire metallurgy has high recovery of mercury and less pollution but spreading the method is still restricted. Hydroetallurgy method is a hot spot in recent research which has diversity of production mode, low energy consumption and strong maneuverability. In the current serious situation of shortage of mercury resources, reduce mercury resources consumption and waste, increase resources recycling are the trend. New recycling process can undoubtedly reduce the waste of mercury resources and establish integrated recycling equipment to make the PVC industry more clear and controllable.

\section{References}

[1] Ura Pancharoena, Sawatpop Somboonpanyaa, Srestha Chaturabula etal. Selective removal of mercury as $\mathrm{HgCl}_{4}{ }^{2-}$ from natural gas well produced water by TOA via HFSLM, J. Journal of Alloys and Compounds, 489 (2010) 72-79.

[2] R.Wen, D.Lei, Z.W. Zhu,etal. Mercury transformation and distribution across a polyvinyl chloride (PVC) production line in China, J. American Chemical Society, 48(2014) 2321-2327.

[3] Z.H.Xue. Mercury pollution control of PVC production by calcium carbide method, J. China Chlor-Alkali,2(2011)25-31.

[4] F.S.Li, X.J.Wang. Pollution and treatment of mercury in calcium carbide based PVC production, J. Polyvinyl Chloride, 43,4(2015)35-39. 
[5] Y.X.Zhang, X.D.Deng, B.Wu. Technological progress in the production of mercuric chloride catalyst in China and the recycle of waste mercuric chloride catalyst in China, J. Polyvinyl Chloride, 36,10(2008) 24-27.

[6] Y.Z.Xu. New technology to recycle waste mercury chloride catalyst, J. Environmental Protection Science and Technology of Guizhou, 2,1(1996)30-33.

[7] Z.H. Mao. China Patent CN103693676A(2014).

[8] Z.Y.Li, Q.S.Li, Z.L.Zhang, etal. China Patent CN203794966U(2014).

[9] Y.R.Qiu, S.Yan. China Patent CN103803638A(2014).

[10] Z.L.Yuan. China Patent CN104263942A(2015).

[11] G.Z.Yu, H.Zhang, X.C.Chen. China Patent CN104451154A(2015).

[12] J.X.Zhu, Y.F.Ren. China Patent CN104438285A(2015).

[13] Y.F.Ren, J.X.Zhu. Leaching behavior and risk control of waste mercury chloride catalyst through mechanochemical reaction using sulfur, J. Environmental Engineering Science,32,9(2015) 816-823. 